\title{
Challenges and New Paradigms in Conservation of Heritage-based Villages in Rural India-A case of Pragpur and Garli Villages in Himachal Pradesh
}

\author{
Preeti Nair ${ }^{1, *}$, Devendra Pratap Singh ${ }^{1}$, Navneet Munoth ${ }^{2}$ \\ ${ }^{1}$ School of Architecture and Planning, Amity University, Noida, 201301, India \\ ${ }^{2}$ Maulana Azad National Institute of Technology, Department of Architecture and Planning, Bhopal, 462003, India
}

\begin{tabular}{l} 
A R T I C L E I N F O \\
\hline Article history: \\
Received: 14 November, 2020 \\
Accepted: 23 January, 2021 \\
Online: 16 February, 2021
\end{tabular}

Keywords:

Rural Heritage

Settlement Morphology

Community Perception

Community Awareness

A B S T R A C T
The research paper aims to focus on the issues and challenges in developing a sustainable
model of an ideal heritage village project by using descriptive and empirical investigation
methods. To capture the perception and understanding of the concept of sustainability of a
Heritage Village, a mixed-methods approach was conducted by the researcher where
document where reviewed, observations were done, structured interviews and a
questionnaire survey was conducted involving resident's in the heritage villages of Pragpur
and Garli in Himachal Pradesh, India. Through this research, the objective was to
catalogues the resident's outlook and understand their belongingness towards their rural
settlement. The analysis conducted, was also to understand their attachment to the heritage
fabric which would act as a catalyst for their sustainable development. Due to the
diversification in terms of architecture, social and cultural aspects, it was important to
analyze the resident's perception towards the built heritage as it may vary to be more or less
important to different people, community groups, or generations.

\section{Introduction}

The term "Heritage" proposes a wider based concept that includes both tangible and intangible heritage as well as the natural ecosystem of the settlement. It includes built environment, historic places and monuments, settlement pattern, settlement morphology, heritage collections, past and present cultural practices including living experiences of the residents of these villages. It can act as a catalyst for the overall sustainable growth and change in these rural settlements [1]. The collective memory of each locality or community or a particular heritage is unique. The preservation, conservation, documentation, presentation of the built heritage, and cultural diversity of any particular place are important challenges.

Manmade structures which possess heritage character and significance should become a part of the built heritage of any settlement and the society [2]. Due to the rapid modernization of the built environment, there is a need for focusing attention to preserve the cultural and architectural heritage, before it disappears completely. Buildings and settlements of historic or architectural value in all urban and rural areas are disappearing

*Preeti Nair, Research Scholar, Amity School of Architecture and Planning, Amity University, Noida, Uttar Pradesh, India, +91 -9711433201,

preetinair30@gmail.com

www.astesj.com

https://dx.doi.org/10.25046/aj0601124 very fast due to neglect and decay or reconstruction in newer materials which results in changing the specific characters of these village cores, leading to monotonous and repetitive new modern constructions.

The built heritage is the prominent aspect to transform the current situation of rural areas because it has the potential to diversify people's perception and acts as a common denominator for the development of these settlements. Heritage can act as a catalyst for the future development and sustainability of a village [3]. It indicates that by enhancing the heritage character of a village, a sustainable tool can be devised for the residents who live in these settlements to make them part of the rural development process. Additionally, the tool is likely to give rural areas a positive, vibrant image and in this way, a trend can be developed for bringing the migrated youth back into these rural areas. It also indicates that cultural meanings and construction assets such as vernacular construction techniques can be mobilized for rural and regional development, and cultural identities can become important for uplifting local economies. 

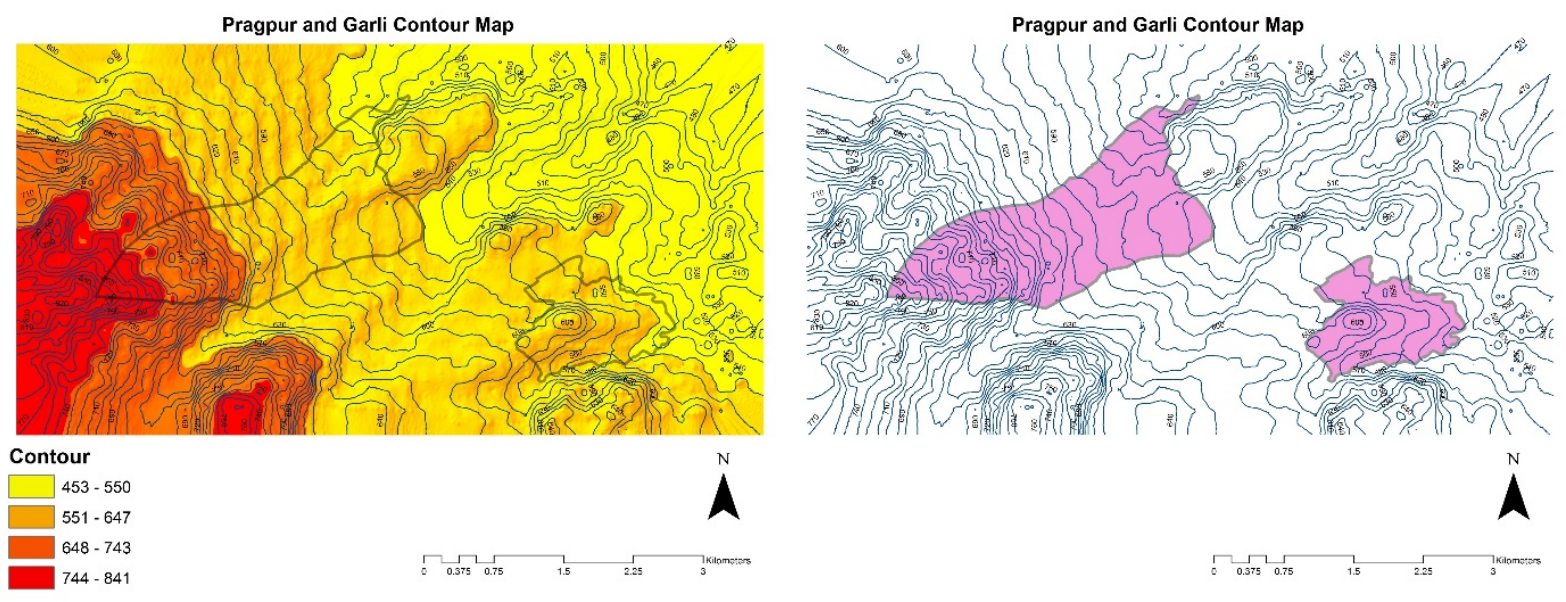

Figure1: Contour Map of Pragpur and Garli geo-referenced on GIS

\section{Methodology}

In the following study, a mixed method of analysis is conducted to investigate the status quo of these villages and also to understand the perception of the residents. In this mixed method of analysis, a three-stage layered analysis is conducted where the first stage is to conduct a spatial analysis using GIS, and then a descriptive and empirical analysis is conducted upon the responses received from the entire sample area. Questionnaire Surveys and interview-based surveys were used as tools to obtain variables. The relevance and public reaction to the concept of being a "Heritage village "models and theories regarding the sustainable built environment were questioned primarily. A total of 100 responses were gathered from these two villages and Turkey Post-Hoc test was conducted on the responses gathered using a five-point Likert scale. The questionnaire was developed on seven major parameters as Economic Viability, Infrastructure, Heritage, Social and cultural Character, Governance/ Policy framework, Environment, Settlement Pattern.

\section{Study Area}

The villages of Pragpur and Garli in Himachal Pradesh are situated at two thousand feet which are approx. 550 Meters above sea level, it comes under the region of district Kangra, Himachal Pradesh. The heritage-based settlement of Pragpur and Garli with a pristine view ideally suited to explore the distinct characteristics of Kangra valley. This area has several water channels that mix into river Beas with its pleasant and comfortable climate, better connectivity, rich flora, and fauna (Figure 1). The Dhauladhar mountain range raised behind this picture of pastoral perfection and needy frames it with tall peaks that are draped with snow for the better part of the year. Recognized as Heritage Village by a notification dated $9^{\text {th }}$ December 1997 the state Government has classified Pragpur and Garli as a "Heritage Zone".

Heritage villages of Pragpur and Garli also fall under the ecozone, ideal for the development of tourism. These villages are also promoted by the administration as an example for community development in the hospitality sector. The core area of Pragpur is notified as "Heritage Villages" by the state government. This makes it one of the villages in India with such a distinctive title. Understanding the unique architectural style and settlement pattern the Government has declared the creation of SADA
(Special Area Development Authority) for improving the infrastructure in the area in the field of tourism[4][5].

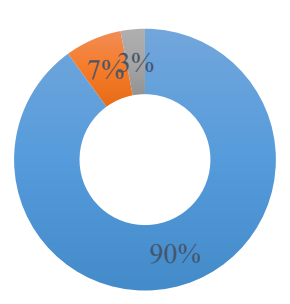

$$
\text { - Residential }
$$

- Commercial

- Tourism

Figure 2: Land use percentage for the village of Pragpur and Garli

\section{Architectural features of the built form}

Pragpur and Garli can be divided into three major sectors based on the activities, such as residential, commercial, and tourism-based buildings (Figure 2). The Residential area is the zone where all the heritage-based residences are built[6]. The commercial area is where all the small-scale activities such as retail activity, weavers, shoemakers, etc. are housed. Tourism based infrastructure is where the residential houses have been converted into small scale hotel. Some of the major features that can be observed within the settlement are, $15 \mathrm{ft}$. that main street is around 15 feet in width which also acts as the main spine for connectivity from the urban centres.7-10 ft wide secondary streets are used for core connectivity towards the interior of the settlement having around 6010 feet width. Low height structures can be observed along the main street usually used for retail purposes.

The layout of the streets is in a linear pattern and the secondary roads radiate from the main street along the natural contour of the settlement. The main axial road of the village consists of built with variable land uses. As per the land use characteristics observed it was seen that the ground floors are used for commercial and retail. The lower floors are designed such as to create a recessed structure and the above floors act as cantilevers. A row of the columnar corridor is constructed supporting the projected floors of the upper storey. A colonnaded facade is recessed which provides easy entry and forms a semi- 
transparent visual screen that creates a unified image of the structures. These plinth areas or semi-open areas act as recreational spots for the shop owners. The upper cantilever storey is used for residential purposes. Most of the residential and commercial structures are not more than two stories. A series of residences having vernacular architectural characteristics are built along the connecting streets of the village which diverge from the main spine. Many of these houses have a central courtyard. The common material used for the construction of these heritage houses are mud plaster, dry and seasoned bamboos with a layer of bitumen for roofing purposes. In the case of repetitive floors, the floors are finished with mud mixed with reed or bhusa to create a thick paste-like consistency. Wood is primarily used for doors and windows. The balustrades on all floors are constructed using seasoned timber. The doors, windows, and even the railings have magnificent ornamentation and carvings designed on them. The door frames are also adorned with carved patterns such as local flowers and flowering buds, animal frescos, and geometrical patterns. Window and door arches are constructed to support the lintel beams. A mixed variety of arches are observed such as segmental arches, flat arches, gothic spires, etc. The chajjas over the openings are also intricately carved. The streets are designed using cobbled stone in interesting patterns. The verandas are also constructed using stones in various patterns like linear, rectangular and circular patterns. The houses are arranged in a row formation around an open to sky courtyard. On the upper floors, the windows are reduced gradually in size. Half-timbered construction is mainly observed in these villages for the construction of residential buildings.
The half-timber construction method is, in which the external and internal walls are constructed using the timber-framed structure and the space between them is filled with materials such as mud plaster, brick, or daub and wattle. In these hilly regions the half-timber construction is usually made of squared oak timbers joined by rafters, tenons, mortises, and wooden pegs; the building's structural skeleton is strengthened using braces in the corners (Table 1).

To understand the evolution of the rural settlement and to catalogue its existence in the rural areas, the help of GIS (Geographic Information System) is taken. First, we created a base map of the spatial database of the Garli village. Then specific attributes such as the timeline of the construction, the year of the last restorations or reconstructions over time, etc. were attached to each vector. The main objective was to identify the residential buildings which were constructed through vernacular style and which residential buildings were renovated with their material study used in construction. In this way, it was possible to generate several maps that emphasize the old village system and the houses which have been abandoned by its residents (Figure 3 and 4). This attribute and the database are updated in real-time, and in this way the government can decide their restoration policies in a more precise way, comparing with the traditional methods. The updated data regarding the preservation and conservation status of residential houses represent an important factor in monitoring, protection and documentation of local heritage and, at the same time, offer the possibility to involve the local community in heritage management for sustainable development.

Table 1: Visual Survey of Pragpur and Garli depicting architectural features

\begin{tabular}{|c|c|c|}
\hline Parameters & Images & Architectural Features \\
\hline $\begin{array}{l}\text { Settlement } \\
\text { pattern }\end{array}$ & 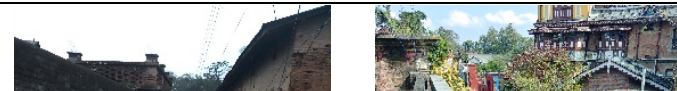 & 1. Streets paved with dressed cobbled stone. \\
\hline Buildings & Tis if & $\begin{array}{l}\text { 2. Gothic spires } \\
\text { 3. Gables with decorative and ornate finials } \\
\text { 4. Wooden pillars and heavy wooden beams } \\
\text { 5. Roofs are sloping, made of local slate on } \\
\text { wooden framework } \\
\text { 6. Gabbled and cross gabbled }\end{array}$ \\
\hline Materials & & $\begin{array}{l}\text { 7. Mud plastered } \\
\text { 8. Slate roofed houses } \\
\text { 9. Bamboo } \\
\text { 10. Reed or bhusa } \\
\text { 11. Cobbled stone }\end{array}$ \\
\hline
\end{tabular}



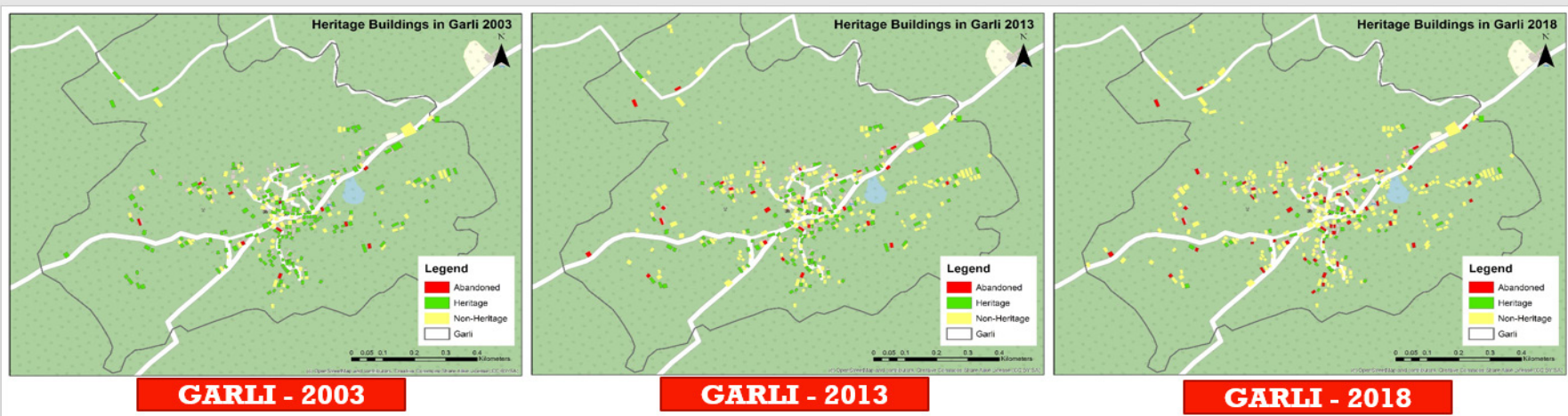

Share of Heritage Buildings 2003

Share of Heritage Buildings - 2013

Share of Heritage Buildings - 2018
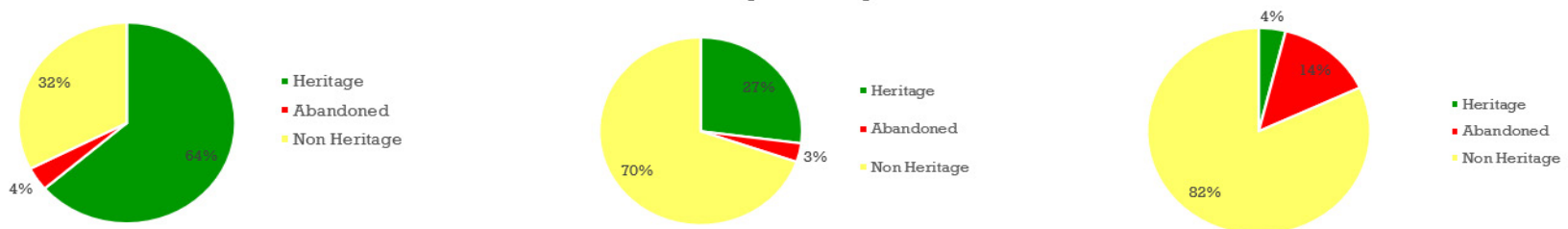

Figure 3- Settlement mapping of built heritage for year 2003,2013,2018 of Garli

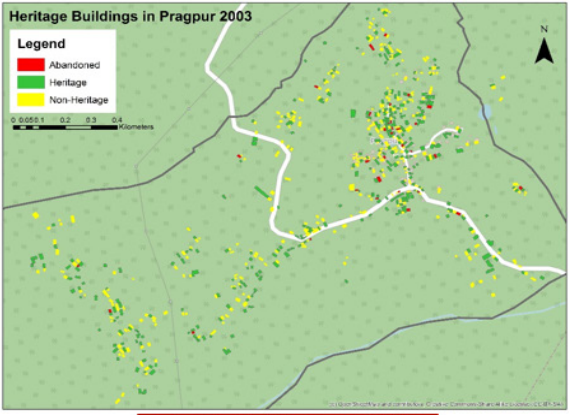

PRAGPUR - 2003

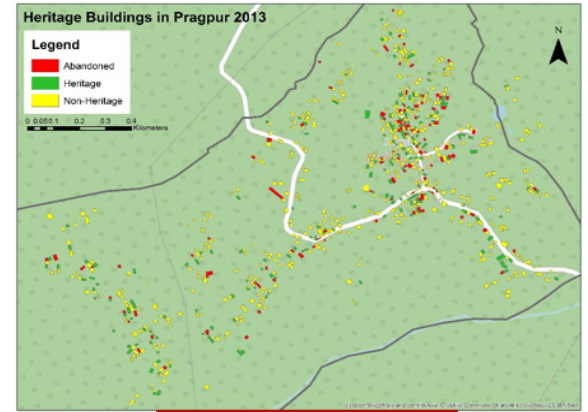

PRAGPUR - 2013

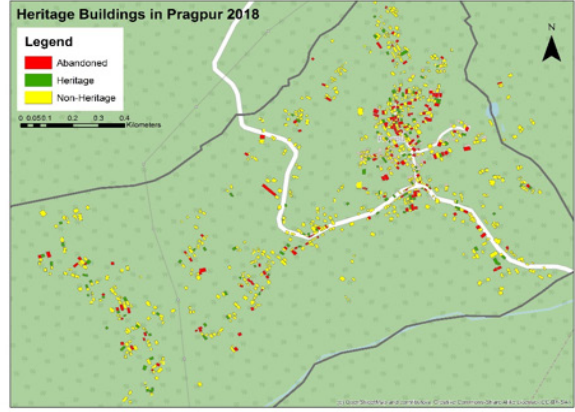

PRAGPUR - 2018
Share of Heritage Building2003

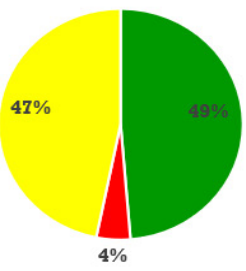

Share of Heritage Building-2013

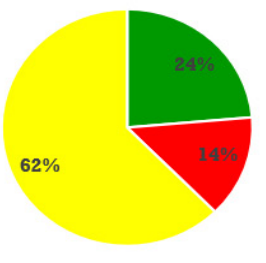

Share of Heritage Building-

2018

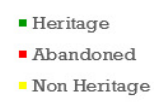

- Heritage

- Abandoned

Non Heritage

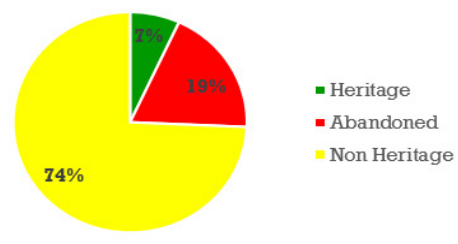

Figure 4: Settlement mapping of built heritage for year 2003,2013,2018 of Pragpur

\section{Data Collection}

To attain a holistic view, 100 interviews (50 in Pragpur and 50 in Garli) were carried out with groups of specialists (including academicians and conservationist), cultural reference groups (including community heads or chieftains, heritage managers, cultural groups, the private hospitality sector, and local NGOs). It is also important to understand that these traditional villages are located near the core and buffer zones of their urban district[7]. The composition of the sample of respondents was taken according to people who have a direct impact due to the development of these villages (Table 2).
The respondents were asked varied questions regarding the status of a "Heritage Village". Also, it reflects the understanding of the respondents as to whether after getting the said status whether the employment opportunities have increased[8]. This study also aims to enrich the literature with an empirical investigation on issues and challenges in developing a sustainable model of heritage village projects[9]. Thus, the objectives are to identify the most common and fundamental issues and challenges that currently exist in these villages and to determine if these issues can be resolved with certain interventions[10]. 


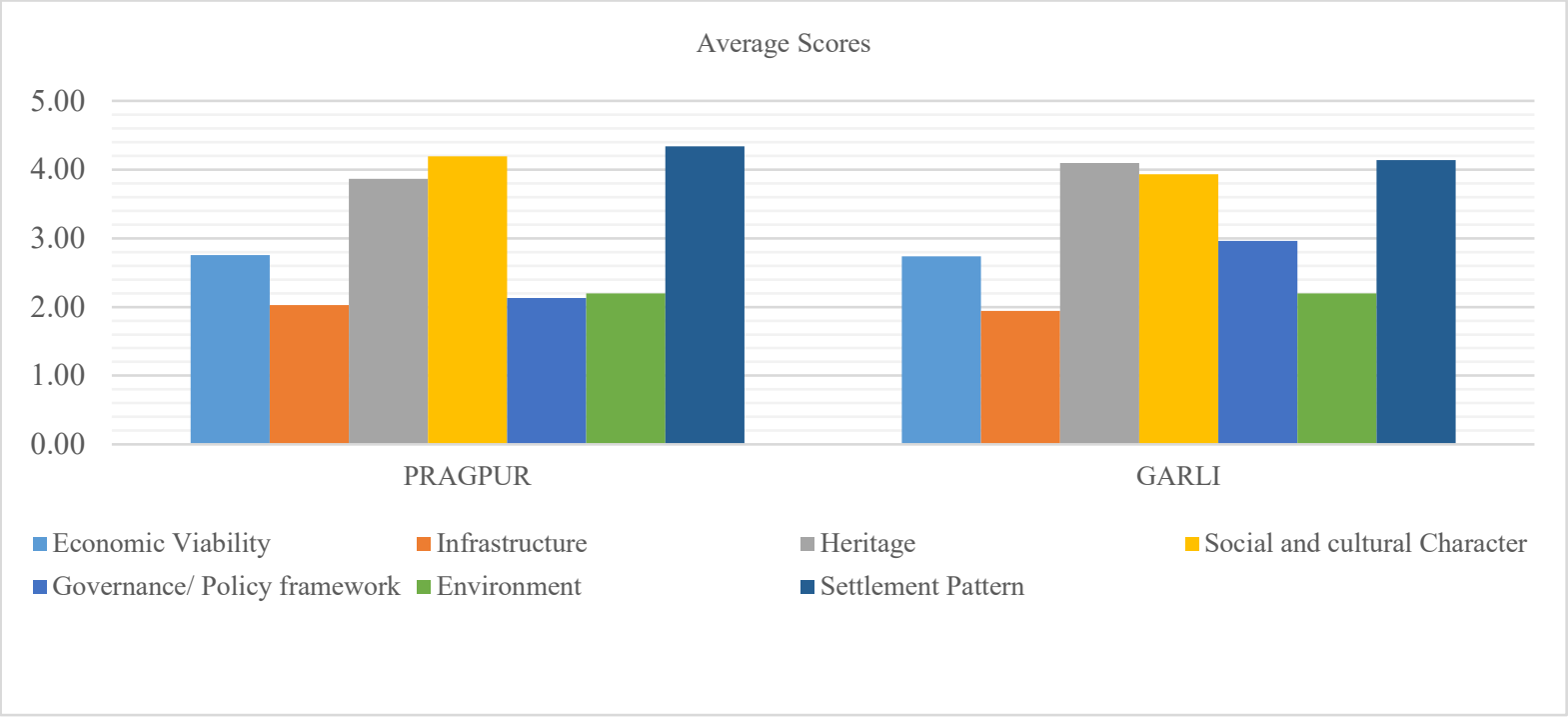

Figure 5: Descriptive analysis for the responses

Table 2: Sample size for the questionnaire survey in Pragpur and Garli

\begin{tabular}{|l|l|l|}
\hline & Pragpur & Garli \\
\hline Total Residential Buildings & 354 & 118 \\
\hline Heritage Building & 93 & 21 \\
\hline New Construction & 261 & 97 \\
\hline Abandoned Residences & 67 & 17 \\
\hline Sample Size for Survey & 50 & 50 \\
\hline
\end{tabular}

\subsection{Statistical analysis}

Statistical analysis is performed by using descriptive and inferential statistics. Pearson correlation was applied to see the relationship between the variables. One-way Anova followed by Tukeys HSD post-hoc test for multiple comparisons was applied to see the mean difference between the villages.

Correlation in the broadest sense is a measure of an association between variables. In correlated data, the change in the magnitude of 1 variable is associated with a change in the magnitude of another variable, either in the same (positive correlation) or in the opposite (negative correlation) direction. The Pearson correlation coefficient is typically used for jointly normally distributed data. Then to understand the study One-way Anova was used.

- To compute large and varied data sets, which included data collected from two different villages and having varied responses. It was also done to verify the variability of the data acquired.

- To test which method yields the most suitable result in the sample of data collected. The sample consisted of stakeholders comprising of the residents, government officials, and tourists in these two villages.

If data are analyzed using ANOVA, and a significant $\mathrm{F}$ value obtained, a more detailed analysis of the differences between the treatment means will be required. In this case, the P-value is less than 0.05 considered as significant at $95 \%$ confidence level.

The statistical software SPSS version 24.0 was used in the analysis. The questions in the questionnaire invited them to indicate the level of agreement of each factor in relation to the seven main parameters based on a five-point scaling, i.e., Strongly Agree $=5$, Agree $=4$, neutral $=3$, Disagree $=2$, and Strongly disagree $=1$.

\section{Result and Discussion}

The Economic Viability parameter, the focus was to correlate the economic fabric [11] of these villages as a community and whether this can act as a prominent factor that governs the sustainable development of a rural area[12]. The Infrastructure parameter focuses on the infrastructure needed for developing a sustainable village model which may include roads, tourism infrastructure, connectivity, etc. The parameter also addresses the negative impact of creating an ideal village model and that may hamper the heritage fabric of the villages[13]. Understanding the relationship and assessing the loss and degradation of the core'sbuilt heritage is the focus behind the Heritage parameter. This is to analyse, investigate, and discuss, the concerns, obstacles, and issues of sustainability to this rural heritage conservation. In the Social and cultural Character parameter the focus is to examine the influence of socio-cultural factors on the formation of architectural spaces in Heritage based villages by applying a descriptive-analytical method and using literature study.

The results of this study indicate that the structural system of traditional houses is based on a hierarchical system and is intricate for the development of the settlement. The Governance/Policy Framework parameter attempts to focus on the holistic system or dynamic model to analyze the interaction of the social-economicheritage sectors to examine policies to achieve the goal of development and conservation. The Literature study shows that conservation alone cannot lead to its own goal. Economic development strategies or policies could be a better choice if the development is carefully planned and effectively controlled to avoid over-consuming resources. 
Table 3: Statistical analysis

\begin{tabular}{|c|c|c|c|c|c|c|c|c|c|c|}
\hline & & \multirow[b]{2}{*}{$\mathrm{N}$} & \multirow[b]{2}{*}{ Mean } & \multirow[b]{2}{*}{$\begin{array}{c}\text { Std. } \\
\text { Deviation }\end{array}$} & \multirow[b]{2}{*}{$\begin{array}{l}\text { Std. } \\
\text { Error }\end{array}$} & \multicolumn{2}{|c|}{$\begin{array}{l}\text { 95\% Confidence } \\
\text { Interval for } \\
\text { Mean }\end{array}$} & \multirow[b]{2}{*}{ Minimum } & \multirow[b]{2}{*}{ Maximum } & \multirow[b]{2}{*}{$\begin{array}{c}\text { p- } \\
\text { value }\end{array}$} \\
\hline & & & & & & $\begin{array}{l}\text { Lower } \\
\text { Bound }\end{array}$ & $\begin{array}{l}\text { Upper } \\
\text { Bound }\end{array}$ & & & \\
\hline \multirow{2}{*}{$\begin{array}{l}\text { Economic } \\
\text { Viability }\end{array}$} & PRAGPUR & 50 & 19.28 & 3.33 & 0.47 & 18.33 & 20.23 & 14.00 & 32.00 & \multirow{2}{*}{$<0.001$} \\
\hline & GARLI & 50 & 19.18 & 2.97 & 0.42 & 18.33 & 20.03 & 12.00 & 25.00 & \\
\hline \multirow[t]{2}{*}{ Infrastructure } & PRAGPUR & 50 & 16.20 & 2.74 & 0.39 & 15.42 & 16.98 & 11.00 & 23.00 & \multirow{2}{*}{$<0.001$} \\
\hline & GARLI & 50 & 15.54 & 2.21 & 0.31 & 14.91 & 16.17 & 11.00 & 20.00 & \\
\hline \multirow[t]{2}{*}{ Heritage } & PRAGPUR & 50 & 23.20 & 3.16 & 0.45 & 22.30 & 24.10 & 15.00 & 29.00 & \multirow{2}{*}{$<0.001$} \\
\hline & GARLI & 50 & 24.58 & 3.14 & 0.44 & 23.69 & 25.47 & 15.00 & 29.00 & \\
\hline \multirow{2}{*}{$\begin{array}{l}\text { Social and } \\
\text { cultural } \\
\text { Character }\end{array}$} & PRAGPUR & 50 & 16.78 & 1.64 & 0.23 & 16.31 & 17.25 & 13.00 & 20.00 & \multirow[b]{2}{*}{$<0.001$} \\
\hline & GARLI & 50 & 15.74 & 2.42 & 0.34 & 15.05 & 16.43 & 10.00 & 20.00 & \\
\hline \multirow{2}{*}{$\begin{array}{c}\text { Governance/ } \\
\text { Policy } \\
\text { framework } \\
\end{array}$} & PRAGPUR & 50 & 4.26 & 1.69 & 0.24 & 3.78 & 4.74 & 2.00 & 7.00 & \multirow[b]{2}{*}{$<0.001$} \\
\hline & GARLI & 50 & 5.92 & 2.15 & 0.30 & 5.31 & 6.53 & 2.00 & 9.00 & \\
\hline \multirow[t]{2}{*}{ Environment } & PRAGPUR & 50 & 2.20 & 1.03 & 0.15 & 1.91 & 2.49 & 1.00 & 4.00 & \multirow{2}{*}{0.017} \\
\hline & GARLI & 50 & 2.20 & 0.97 & 0.14 & 1.92 & 2.48 & 1.00 & 4.00 & \\
\hline \multirow{2}{*}{$\begin{array}{l}\text { Settlement } \\
\text { Pattern }\end{array}$} & PRAGPUR & 50 & 4.34 & 0.80 & 0.11 & 4.11 & 4.57 & 3.00 & 5.00 & \multirow{2}{*}{0.012} \\
\hline & GARLI & 50 & 4.14 & 0.93 & 0.13 & 3.88 & 4.40 & 2.00 & 5.00 & \\
\hline
\end{tabular}

Understanding the influence of human behavior on the landscape is the prime objective of the Environment parameter. Also, to analyze the reason for village landscape transition which come from road construction, the transformation of building materials, higher living level, the inflection of family structure and social relationship, different culture and self-identity [14]. To investigate or to identify the challenges and hurdles towards the growth or deterioration of the settlement of heritage villages, it was gathered that through cataloguing the settlement pattern the evolution of the community and its historical background can be documented with its various changes in all its bearings.

To understand the aim of the Economic Viability parameter was to determine their economic status of the respondents and whether they have benefitted from the status of "heritage village" [15]. The respondents of the villages of Garli and Pragpur had major concerns while developing their residential buildings. The families owning these houses lacked the economic resources and finances to maintain these houses [16]. While enquiring about the infrastructure development the residents were not content and strongly disagrees with the increase in any land value in villages of Garli and Pragpur in Himachal where the circle rate for 100 sq. meters are around $886 \mathrm{Rs}$ and 1751 Rs (District Kangra, Government of India website) respectively from last one decade.

It indicated the stagnation in terms of development. In these villages, it was also observed that mostly the migrant population is residing in the heritage houses were on a rental basis [17]. They are mostly not aware of the heritage status and do not have the economical means to maintain these residential buildings. The infrastructure needed to sustain and develop a heritage village was not visible in these Villages.

Community Participation has been observed as a major factor for the sustainable development of a settlement [18]. In villages like Garli, some residential patrons have tried to restore their residential buildings and convert them into commercial and recreational spaces for the tourist, parallel developing the village and generating employment for the locals. The basic amenities such as fire protection and police protection also lack in these villages. The villagers were governed under Panchayat System and they themselves resolve the petty issues related to the governance of the villages [19].

The villages lacked the basic infrastructure to support a tourist influx. It was determined by the study that, many people outside of these villages are not aware of the heritage status. The upkeep the vernacular architectural style of the residences, not many skilled labours are available. The construction and maintenance in these villages are done according to the new construction style using materials such as RCC and Bricks. In Pragpur and Garli, timber construction and wood such as teak and sheesham were used for the construction of residential houses.

\section{Findings}

The major factors highlighted in this study were as detailed below:

- The first major criteria were to identify the heritage-based settlements through the extensive literature study. A multidisciplinary approach was initiated where along with the architectural characters certain parameters were combined such as economy, social conditions, settlement morphology, etc.

- It was also observed that different policy development schemes or frameworks for the inclusion of rural heritage preservation measures is not highlighted or mentioned. There is no incorporation of heritage-based rural development in the physical planning processes as part of a holistic approach towards sustainable development [20]. This research wants to focus on and promote the inclusion of preservation of heritage-based residential buildings representing the local architectural style. 
- Finally the study wants to highlight the importance of heritage in rural development. Through the descriptive and empirical study of the data, it was found that for the development of these types of settlements the role of the local residents and community plays an important part [21]. There is a need for introducing public awareness as a tool to generate employment in these rural areas.

The data acquired through the questionnaire survey along with the interview survey gave many insights to identify the hurdles and challenges while implementation of heritage-based development policy. A multidisciplinary approach as mentioned earlier can be used where collaboration with tourism, hospitality industry all related sectors can be initiated [22]. This was considered important to resolve any issues which may cause the undermining preservation of the built resources. It is also stressed that preservation of cultural and natural heritage should be perceived together and they must not be promoted with activities that can cause hindrances towards sustainability. To make the residents conscious about the values of rural heritage certain programs can be initiates such as studies on vernacular architecture, promotion of knowledge, and training about traditional techniques and materials.

It was also observed during the survey that the majority of participants were of the suggestion that a balance should be maintained between the retained heritage-built fabric and its economic viability. The entire exercise was conducted to understand the importance of the residential buildings and should actually be protected. Secondly, it was to address its importance for the future generations of these villages. The second factor also ponders upon the different methods of adaptability and reuse of these heritage buildings. The process also helped to understand the hurdles along with the decision-making towards the protection and conservation of these buildings. Many respondents have also agreed that the policymakers and government officials should ensure that if the value of a residential building is under heritage significance then relevant heritage policies and bye-laws should be formulated.

\section{Conclusion}

Through the extensive literature study regarding the preservation of this built heritage, the researcher had identified core parameters that are vital for sustainable development. The qualitative study and empirical study evaluated the study and the observation done to understand the ground reality. The major parameters were categorized into several sub-parts depending on the focus, such as historical value, economic viability, infrastructure, socio-cultural characteristics, and the overall aesthetic value. The research aimed to understand the perception of the local community and analyse their approach and consensus to further develop a holistic policy framework. The detailed analysis led to the determination that the infrastructure lacks the capacity to promote tourism or hospitality industry to create a sustainable model to promote the heritage of that area. In very few cases, the architectural value (vernacular architectural style) is also considered but all are linked to the history of a particular settlement along with its cultural values.

It is evident from the analysis from the sample groups and interviews that diversity plays an important role when discussing the importance of their heritage settlement. It varies across the communities, geographical location. It also varied because of their economic status, socio- cultural parameters as seen in these villages of Pragpur and Garli. As per the investigation, it was also highlighted that administration plays an important role as policymakers and implementors. It is important for the local government to create awareness towards the importance of these heritage-based residential buildings and that they may gain value in the future.

\section{References}

[1] S.H. Zolfani, E.K. Zavadskas, "Sustainable development of rural areas' building structures based on local climate," Procedia Engineering, 57, 12951301, 2013, doi:10.1016/j.proeng.2013.04.163.

[2] E. Erdogan, S.D.B. Erkiş, "Sille settlement in the context of sustainable historical fabric and façade analysis of its traditional houses," Archnet-IJAR, 8(3), 117-135, 2014, doi:10.26687/archnet-ijar.v8i3.214.

[3] I. Syahrul, M. Radzuan, N. Fukami, Y. Ahmad, "Cultural heritage, incentives system and the sustainable community: lessons from Ogimachi Village, Japan.," Cultural Heritage, Incentives System and the Sustainable Community: Lessons from Ogimachi Village, Japan., 10(1), 130-146, 2014.

[4] R.P.B. Singh, M. Fukunaga, "The \{World\} \{Heritage\} \{Villages $\}$ $\{$ Shirakawa $\}-\{\mathrm{G} \overline{0}\}$ and $\{$ Gokayama $\},\{$ Japan $\}:\{$ Continuing $\}$ Culture $\}$ and \{Meeting\} \{Modernity\}," Heritagescape and Cultural Landscapes. Planet Earth \& Cultural Understanding Series, Pub, 6(Special Lecture 3), 129-150, 2010

[5] S. Kim, "World Heritage Site designation impacts on a historic village: A case study on residents' perceptions of Hahoe Village (Korea)," Sustainability (Switzerland), 8(3), 2016, doi:10.3390/su8030258.

[6] C. Holtorf, "Embracing change: how cultural resilience is increased through cultural heritage," World Archaeology, 50(4), 639-650, 2018, doi:10.1080/00438243.2018.1510340.

[7] N. Mitsche, F. Vogt, D. Knox, I. Cooper, P. Lombardi, D. Ciaffi, "Intangibles: Enhancing access to cities' cultural heritage through interpretation," International Journal of Culture, Tourism, and Hospitality Research, 7(1), 68-77, 2013, doi:10.1108/17506181311301381.

[8] N.A. Haddad, L.A. Fakhoury, "Towards developing a sustainable heritage tourism and conservation action plan for irbid's historic core," ArchnetIJAR, 10(3), 36-59, 2016, doi:10.26687/archnet-ijar.v10i3.1035.

[9] S. Prompayuk, P. Chairattananon, "Preservation of Cultural Heritage Community: Cases of Thailand and Developed Countries," Procedia - Social and Behavioral Sciences, 234, 239-243, 2016, doi:10.1016/j.sbspro.2016.10.239.

[10] R. Askarizad, "Influence of Socio-Cultural Factors on the Formation of Architectural Spaces ( Case Study : Historical Residential Houses in Iran ) Influence of Socio-Cultural Factors on the Formation of Architectural Spaces," 1(May), 44-54, 2019.

[11] O.S. Asfour, A.T. Hathat, "Strategies of Sustainable Rural Development in the Gaza Strip : Wadi Gaza Town as a Case Study STRATEGIES OF SUSTAINABLE RURAL DEVELOPMENT IN THE GAZA STRIP : WADI GAZA TOWN AS A CASE STUDY," (August), 2016.

[12] G.A.. Tanguay, E. Berthold, J. Rajaonson, "A Comprehensive Strategy to Identify Indicators of Sustainable Heritage Conservation,” Les Cahiers Du CRTP (Workin Paper), (September), 2014.

[13] S. Roy, "Regional Disparities in Growth and Human Development in India," (September), 2012.

[14] I.S. Mat Radzuan, S. Inho, Y. Ahmad, "A rethink of the incentives programme in the conservation of south korea's historic villages," Journal of Cultural Heritage Management and Sustainable Development, 5(2), 176201, 2015, doi:10.1108/JCHMSD-02-2014-0006.

[15] M. A. S., "Efficient Rural Development Strategies for the Improvement of Indian Economy," International Journal of Pure \& Applied Bioscience, 5(6), 566-570, 2017, doi:10.18782/2320-7051.5462.

[16] N.A. Haddad, F.Y. Jalboosh, L.A. Fakhoury, R. Ghrayib, "Urban and rural umayyad house architecture in Jordan: A comprehensive typological analysis at Al-Hallabat," Archnet-IJAR, 10(2), 87-112, 2016, doi:10.26687/archnet-ijar.v10i2.835.

[17] I.K. Suarthana, N. Madiun, S.O. Yuniarsa, "Exploring The Community Participation, Tourism Village, And Social-Economic To Environment Impact (Case Study: Pentingsari Village, Yogyakarta)," International Journal of Business and Management Invention, 4(9), 85-90, 2015. 
[18] A.J. Imperiale, F. Vanclay, "Using Social Impact Assessment to Strengthen Community Resilience in Sustainable Rural Development in Mountain Areas," Mountain Research and Development, 36(4), 431-442, 2016, doi:10.1659/MRD-JOURNAL-D-16-00027.1.

[19] I.S. Mat Radzuan, Y. Ahmad, "Synthesising an effective incentives system in safeguarding the heritage village of melaka and george town," Planning Malaysia, (5), 157-168, 2016, doi:10.21837/pmjournal.v14.i5.200.

[20] X. Honggang, "Exploring Sustainable Policies for Xidi, the World Heritage Village ," Proceedings of the 28th International Conference of the System Dynamics Society, 1-16, 2010.

[21] J. Hosagrahar, J. Soule, L.F. Girard, A. Potts, "International Council on Monuments and Sites (ICOMOS) Cultural Heritage, the UN Sustainable Development Goals, and the New Urban Agenda," 2016.

[22] L. Yan, C. Liang, H. Zhiwen, "Conservation of Historical and Cultural Towns and Villages in China," Aussie-Sino Studies, 3(4), 85-97, 2017. 